\title{
Y chromosome effect on prenatal live weight growth of laboratory minipigs
}

\author{
Kirill Shatokhin ${ }^{1 *}$, Sergey Nikitin ${ }^{2}$, Sergey Knyazev ${ }^{3}$, Vera Zaporozhets ${ }^{2}$ and Sergey \\ Pashkovskiy $^{l}$ \\ ${ }^{1}$ Novosibirsk State Agrarian University, Laboratory of Enzyme Analysis and DNA Technologies \\ 630039, St. Dobrolyubova, 160, Novosibirsk, Russia. \\ ${ }^{2}$ Institute of Cytology and Genetics of Siberian Department of Russian Academy of Sciences \\ Laboratory of Molecular Genetics and Breeding of Farm Animals, 630090, Ave. Lavrentieva, 10, \\ Novosibirsk, Russia. \\ ${ }^{3}$ Novosibirsk State Agrarian University, Department of breeding, feeding and particular animal \\ husbandry 630039, St. Dobrolyubova, 160, Novosibirsk, Russia.
}

\begin{abstract}
This paper describes the results of the influence of Ychromosome gene complex on pre- and postnatal growth of piglets of laboratory mini-pigs ICG SB RAS. Breeding group includes four genealogical lines of boars united by a successive father-son relationship. Three lines: MS2853, MS2987, and VTN300 inherited their Y chromosomes from boars of Vietnamese-South Asian breed. The fourth line (LNDR07) received Y chromosome from the Landrace boar. This study revealed that all three lines of boars carrying Asian Y chromosome did not differ in weight of newborn offspring, while the weight and, correspondingly, prenatal growth of newborns of boars carrying European $\mathrm{Y}$ chromosome were statistically significantly less. Thus, at this stage of research, there is reason to believe that the selection group of mini-pigs ICG SB RAS contains polymorphism in the complex of Y-chromosome genes involved in the control of prenatal growth process. An assumption was considered that growth retardation during prenatal and early postnatal periods, as well as an increased proportion of culled offspring of boars carrying European Y chromosome can be caused by poor compatibility of its gene complex with the allele pool inherited from the mini pigs ICG SB RAS from Vietnamese breed.
\end{abstract}

\section{Introduction}

In mammals, $\mathrm{Y}$ chromosome is a structure that has lost significant part of genes due to an immune conflict with $\mathrm{X}$ chromosome genes [1-3]. The frequency of crossing-over between $\mathrm{X}$ and $\mathrm{Y}$ chromosomes is significantly lower than between autosomes [4] what makes it possible to sustainably inherit traits controlled by genes specific for $\mathrm{Y}$ chromosome. Genes responsible for the function of spermatogenesis, male sexual activity, fertility and the development of male body as a whole are located on Y chromosome [1, 5-8]. In mice, a relationship was found between such traits as live weight and livability with the

\footnotetext{
*Corresponding author: true_genetic@mail.ru
} 
polymorphism of $\mathrm{Y}$ chromosome loci [9]. In domestic pigs, erythrocyte antigen polymorphism associated with sex chromosomes was described which is controlled by both homologous and non-homologous regions of X and Y chromosomes [10]. The presence of a factor was shown that provides males with a larger weight at birth $[11,12]$. It is possible that he $\mathrm{Y}$ chromosome is a rather significant factor determining birth weight in a small and highly inbred population.

Laboratory mini-pigs have recently been recognized as a rather promising model for biomedical experiments [13-16]. Their herds, as a rule, are small closed populations where genealogical lines of boars and sows families are still distinguished [17, 18]. Lines and families have unique genetic structures: each line carries a Y-chromosome which son exclusively inherits from father; each family has a unique mitochondrial genome which daughter inherits from mother [19]. It was previously shown that, in conditions of a small, closed, highly inbred population, the variability of a priori polygenic traits can be determined by polymorphism of a relatively small number of loci [20]. Thus, an assessment of the influence of the unique fragments of the genome of males and females ( $\mathrm{Y}$ chromosome and mitochondrial DNA) on the development of some phenotypic features seems to be a quite logical and relevant research.

The aim of this study is to assess the effect of Y chromosome on prenatal growth of mini-pigs of the ICG SB RAS. Specific objective of the study is to compare four (three with Asian and one with European Y-chromosome) genealogical lines of boars according to the live weight of their descendants at birth and at one month of age.

\section{Materials and methods}

Material for the study included the data of zootechnical registration of piglets $(n=1835)$ during suckling period (298 nests) in the breeding group of mini-pigs of the ICG SB RAS for the period from 2013 to 2018. This breeding group of mini-pigs is kept in "Mini-Pig Farm" of the Federal Research Center Institute of Cytology and Genetics of the Siberian Branch of the Russian Academy of Sciences (ICG SB RAS) in the suburban area of Novosibirsk, in the village of Kainskaya Zaimka, Russia. Animals are kept on concrete floors, with sawdust used as bedding, in a brick pig house heated during winter season. Temperature in the pig house was maintained in the range of $18-25^{\circ} \mathrm{C}$ throughout the year what corresponds to the standards for keeping adult pigs [21]. During the suckling period the piglets did not receive additional feeding. There are infrared lamps for local heating in the machines where suckling piglets are kept. Feeding of lactating sows is carried out with concentrates consisting of bran, wheat stock feed and boiled meat waste. The content and ratio of nutrients in this feeding corresponded to the standards for feeding pigs and is calculated on a live weight of $50-80 \mathrm{~kg}$ [22]. All animals were separately weighed at birth and at one month of age. There is a special registration log book of animals' livability where the date and reason for withdrawal are specified.

Mini-pigs of the ICG SB RAS are a small, highly inbred group originating from 5 sowsfounders of large white breed (KB 1902, KB1906, KB 1910, KB1912, KB1926), three Svetlogorsk (MS2853, MS2913 and MS2987), two Landrace (LNDR03 and LNDR07), and two Vietnamese (VTN300 and VTN3001) boars [17, 23, 24]. This herd contains four genealogical lines of boars: MS2853, MS2987, LNDR07 and VTN300 named for the breed and number of their founder. The number of basic, tested and replacement sows in different years ranged from 30 to 40 , of boars - from 5 to 15 . Similarity index between animal breeding group calculated by "blood shares" of founders varies from 0.9 to 1.0 [17]. Thus, there is reason to believe that, in general, genetic pool of the group is substantially aligned, and the differences revealed between the genealogical lines of boars are most likely due to the difference in the genetic content of their Y chromosomes. 
Contribution to reproduction was defined as the part of offspring of a particular line from the total number of newborn piglets. Parameters of descriptive statistics were calculated by common methods [25]. Belonging of sample variances to a single population was evaluated using Bartlett's test [26]. Significance of differences in parameters was determined using Student's test [25]. Error of a qualitative character expressed as percentage was calculated using a special formula [27]. Calculations were performed using Microsoft Excel 2007 software. Results of single-factor analysis of variance were evaluated by means F-test calculated using ANOVA application included in the STATISTICA8 software package.

\section{Results and Discussion}

Comparison of intergroup dispersions in live weight of newborn piglets in the genealogical lines of mini-pigs at the ICG SB RAS (factor gradations) showed that they belong to the same general population (Bartlett's criterion $\chi^{2}=3.483 ; d . f$. $=70$ ), i.e., the suitability of data array for the analysis of variance. In turn, analysis of variance revealed statistical significance of the influence of linear affiliation of fathers on the weight of their offspring at birth (F-test $F=5.36 ; \mathrm{P}=0.001128$ ). Thus, the genealogical lines of boars of mini-pigs of the ICG SB RAS differ in the average weight of newborn piglets while variation in trait values inside these lines is approximately the same and is due to random factors (Table 1).

Table 1. Live weight of newborn descendants of mini-pig boars of the ICG SB RAS from different genealogical lines $(\mathrm{g})$

\begin{tabular}{|c|c|c|c|c|c|c|}
\hline \multirow{3}{*}{ Parameter } & \multicolumn{4}{|c|}{ Genealogical line } & \multirow{3}{*}{$\begin{array}{c}\text { Asian } \\
\text { Ychromosome, } \\
\text { total }\end{array}$} & \multirow{3}{*}{$\begin{array}{l}\text { Student's } \\
\text { test }^{*}\end{array}$} \\
\hline & \multicolumn{3}{|c|}{ Asian Y chromosome } & \multirow{2}{*}{$\begin{array}{c}\begin{array}{c}\text { European } \\
\text { Ychromosome }\end{array} \\
\text { LNDR07 }\end{array}$} & & \\
\hline & MS2853 & MS2987 & VTN300 & & & \\
\hline $\begin{array}{l}\text { Number of } \\
\text { subjects }(n)\end{array}$ & 374 & 741 & 312 & 408 & 1427 & - \\
\hline $\operatorname{Mean}\left(X \pm s_{x}\right)$ & \begin{tabular}{|c|}
$687.553 \pm$ \\
7.102 \\
\end{tabular} & $\begin{array}{c}701.229 \pm \\
4.878\end{array}$ & \begin{tabular}{|c|}
$687.163 \pm$ \\
7.356 \\
\end{tabular} & $667.843 \pm 7.088$ & $694.569 \pm 3.526$ & $3.38 \mathrm{P}<0.001$ \\
\hline Dispersion $\left(S^{2}\right)$ & 18815.609 & 17399. & 16827.797 & 20447.856 & 17741.429 & - \\
\hline $\begin{array}{l}\text { Difference of mean } \\
\text { with desired value } \\
(700 \mathrm{~g})\end{array}$ & -12.447 & 1.229 & -12.837 & -32.157 & -5.431 & $3.38 \mathrm{P}<0.001$ \\
\hline $\begin{array}{l}\text { Significance of the } \\
\text { difference between } \\
\text { the mean and the } \\
\text { desired value } \\
\text { (Student's test) }\end{array}$ & 1.75 & 0.25 & 1.75 & $4.54 \mathrm{P}<0.001$ & 1.54 & - \\
\hline $\begin{array}{l}\text { Contribution to } \\
\text { reproduction in } \\
2013-2018(\%)\end{array}$ & $15.15 \pm 2.08$ & $45.89 \pm 2.89$ & $14.28 \pm 2.03$ & $24.68 \pm 2.50$ & $75.32 \pm 2.50$ & $\begin{array}{c}13.41 \\
\mathrm{P}<0.001\end{array}$ \\
\hline
\end{tabular}

*This refers to the relevance of differences between the carriers of European and Asian $Y$ chromosomes.

To determine the line that is not related to the general population, pair wise comparisons of intergroup average values of the weight of newborns were carried out (Table 2). As a working hypothesis, it was suggested that the observed phenomenon may be due to the different origin of Y chromosomes in the breeding group of mini-pigs of the ICG SB RAS. Boars of MS2853 and MS2987 lines have Y chromosome of the Svetlogorsk group of minipigs which was inherited from Minisibs group bred by crossing Vietnamese boars with 
Landrace sows. VTN300 line also received its Y chromosome from the Vietnamese breed. It follows that the boars of MS2853, MS2987, and VTN300 lines have Y-chromosomes of South East Asian origin which was conditional lydefined as "Asian Y chromosome" (Table 1). LNDR07 line received Y chromosome from European Landrace boar, that is, it has a conditionally European Y chromosome (Table 1); gene content of it may differ from the South East Asian, as was shown in some studies [28]. If Y chromosome is able to influence on prenatal growth, then there should be differences between LDPR07 line and MS2853, MS2987, and VTN300 lines.

Result of pair wise comparisons is consistent with the hypothesis under consideration LNDR07 line is "falling out" of the general population while differences between MS2853, MS2987, and VTN300 lines are not significant (Table 2). Thus, pig Y-chromosome, as well as that in mice [9], is able to control a certain part of the variability of live weight. Accordingly, there are quite good reasons to claim the presence of polymorphism of at least one of Y chromosome genes that cause these differences (see Tables 1,2). Studies [28] indicate polymorphism of four $\mathrm{Y}$ chromosome genes of domestic pigs: USP9Y, UTY, $A M E L Y$, and EIF2s3Y. Based on available data [29-32], none of them seems to be an obvious candidate who could determine revealed interlinear differences (Table 1,2).

Table 2. Determination of a genealogical line of boars of mini-pigs at the ICG SB RAS that is not related to the general population by weight of a newborn and comparison of the contribution of lines to herd reproduction

\begin{tabular}{|c|c|c|c|c|}
\hline \multicolumn{5}{|c|}{ Weight of newborn } \\
\hline Breeding line & MS2853 & MS2987 & VTN300 & LNDR07 \\
\hline MS2853 & & 1.59 & 0.04 & $1.964 \mathrm{P}<0.05$ \\
\hline MS2987 & $8.63 \mathrm{P}<0.001$ & & 1.59. & $3.88 \mathrm{P}<0.001$ \\
\hline VTN300 & 0.30 & $8.95 \mathrm{P}<0.001$ & & 1.89 \\
\hline LNDR07 & $2.93 \mathrm{P}<0.01$ & $5.55 \mathrm{P}<0.001$ & $3.23 \mathrm{P}<0.01$ & \\
\hline \multicolumn{5}{|c|}{ Contribution to herd reproduction } \\
\hline
\end{tabular}

To evaluate the effectiveness of artificial selection by the large size of piglets in the genealogical lines of boars, a comparison was made of sample means with a desirable selection trait value of $700 \mathrm{~g}$ [17]. Since the desirable selection trait value is an arbitrary constant with an error equal to zero, the reliability of sample mean deviation from this value was evaluated by dividing the obtained difference by the error of mean. Comparison showed the absence of significant differences for MS2853, MS2987 and VTN300 lines while mean value in in LNDR07 line was significantly less than desirable (Table 1). Thus, artificial selection by the large size of piglets was successful in lines carrying Asian (Vietnamese) Y chromosome and significantly less effective in lines carrying of European Y-chromosome (Table 1). However, this is not surprising, since the ratio of contributions of carriers of Asian and European Y chromosomes to the herd reproduction from 2013 to 2018 is approximately 3:1 (Table 1). Consequently, the selection result is quite natural - carriers of European Y chromosome lag in the efficiency of artificial selection for the large size of piglet; it is obviously due to their smaller contribution to the reproduction of herd. There is another interesting thing. The contribution of MS2853 and VTN300 lines to herd reproduction is significantly smaller than that of MS2987 line but the differences in the average weight of newborn offspring between them are statistically insignificant, and artificial selection for the large size of piglets is characterized by the same effectiveness. At the same time, LNDR07 line whose contribution to herd reproduction is statistically higher than in MS2853 and VTN300 lines has a statistically significantly lower average weight of newborn offspring and effectiveness of artificial selection (Tables 1,2). Obtained result is 
somewhat paradoxical. LNDR07 line carrying Y-chromosome of European Landrace breed with large size of newborns (1323 $\pm 2 \mathrm{~g})$ [20] statistically has a significantly less average weight of a newborn than MS2853, MS2987 and VTN300 lines with Y-chromosome of

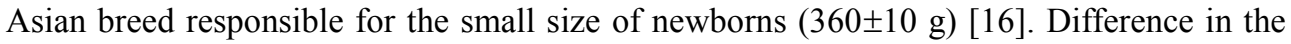
effective influence of Asian and European Y chromosomes on the weight of newborn piglet in the breeding group of mini pigs of the ICG SB RAS is $26.726 \pm 7.917$ grams (Table 1).

Based on literature, let us evaluate the contribution of non-Y-chromosome factors of European origin to the weight of a newborn. For this, we defined two quantities:

1. Difference between the weight of a newborn Landrace piglet and of a piglet of mini-pigs of the ICG SB RAS who carry European Y-chromosome;

2. Difference between the weight of a newborn Vietnamese piglet and of a piglet of mini-pigs of the ICG SB RAS who carry Asian Y-chromosome;

The first value shows a part of European non-Y-chromosomal contribution to the intensification of prenatal growth absentin mini-pigs of the ICG SB RAS, the second value shows the retained one. Values obtained are equal to: the first - to $655.157 \pm 7.365 \mathrm{~g}$, the second -to $334.569 \pm 10.603 \mathrm{~g}$. Their sum is $989.726 \pm 12.910$ grams, and is the sought-for value of European non-Y chromosome contribution to the prenatal growth of domestic pigs (Table 3). For the convenience of calculations, we expressed the values found as a percentage of the weight of a newborn Landrace piglet of 1,323 g (Table 3) obtained on a representative sample of 21,618 animals [20]. Effect size of the intensification of prenatal growth controlled by European non-Y chromosome genes is $74.809 \pm 0.976 \%$, the share of this contribution to the weight of a newborn piglet lost in the mini-pigs of the ICG SB RAS is $49.521 \pm 0.557 \%$, and retained value is $25.289 \pm 0.801 \%$. The latter value substantially coincides with the total share of the allele pool of the large form of domestic pig in the mini-pig gene pool of the ICG SB RAS which is $26 \%$ [23]. Difference between the efficiency of European and Asian Y chromosomes in this case was $2.020 \pm 0.598 \%$.

Table 3. Contributions of $Y$ - and non-Y chromosomal factors to the weight of a newborn piglet in Landrace and Vietnamese breeds

\begin{tabular}{|c|c|c|c|}
\hline \multirow{2}{*}{$\begin{array}{c}\text { Contribution to the weight of a } \\
\text { newborn }\end{array}$} & \multicolumn{3}{|c|}{ Amount of components } \\
\cline { 2 - 4 } & In g & \multicolumn{2}{|c|}{ In \% of the weight of a newborn } \\
\cline { 2 - 4 } & & Landrace $(1323 \mathrm{~g})$ & Vietnamese $(360 \mathrm{~g})$ \\
\hline European Y chromosome & $43.196 \pm 3.055$ & $3.265 \pm 0.2309$ & - \\
\hline $\begin{array}{c}\text { European specific non-Y } \\
\text { chromosome factors }\end{array}$ & $989.726 \pm 12.910$ & $74.809 \pm 0.976$ & - \\
\hline $\begin{array}{c}\text { Non-Y chromosome factors } \\
\text { common to European and Asian } \\
\text { genome }\end{array}$ & $290.078 \pm 13.115$ & $21.926 \pm 0.991$ & $80.577 \pm 3.643$ \\
\hline Asian Y chromosome & $69.922 \pm 8.486$ & $5.285 \pm 0.641$ & $19.423 \pm 2.357$ \\
\hline
\end{tabular}

Previous studies revealed that the weight difference between newborn males and females in Landrace pigs (that is, the effect of European Y chromosome in its pure form) is $3.265 \pm 0.2309 \%$ [20]. Adding this value to the established in this study difference between the contributions of European and Asian Y chromosomes $(2.020 \pm 0.598 \%$ ), we obtain the contribution of Asian $\mathrm{Y}$ chromosome genes to the weight of a newborn piglet equal to $5.285 \pm 0.641 \%$ (Table 3). Further, it is possible to evaluate the contribution of non-Y chromosomal genes common to European (Landrace) and Asian (Vietnamese) breeds to the weight of a newborn piglet. For this, we subtract the contribution of Asian Y chromosome from the weight of a newborn piglet of Vietnamese breed. Obtained value is equal to $21.926 \pm 0.991 \%$ and will be the contribution of non-Y chromosomal genes common to European and Asian breeds to the weight of a newborn piglet (Table 3). Then, the 
contributions of Asian $\mathrm{Y}$ chromosome and non-Y chromosome factors common to European and Asian genome were recalculated for the weight at birth of Vietnamese piglets (Table 3). It turned out that the relative contribution of gene complex of $\mathrm{Y}$ chromosome in Asian breed far exceeds the similar value of European breed (19.423 \pm 2.357 and $3.265 \pm 0.2309$ ). That is, the breeding value of $Y$ chromosome genes is high in South Asian Vietnamese breed and vanishingly small in North European one. Perhaps this reflects two different breeding strategies. In Vietnamese breed, high contribution of Y chromosome to the weight gain of males during prenatal period can to some extent compensate for the later consequences of reverse sex dimorphism in weight (adult males are smaller and weigh less than females) [33]. In European pigs, due to the lack of need for such an influence, Y chromosome is practically not involved in prenatal growth.

Table 4. Live weight $(\mathrm{kg})$ of descendants of boars of mini-pigs of ICG SB RAS of different genealogical lines, 1 month

\begin{tabular}{|c|c|c|c|c|c|c|}
\hline \multirow{3}{*}{ Parameter } & \multicolumn{4}{|c|}{ Genealogical line } & \multirow{3}{*}{$\begin{array}{c}\text { Asian Y } \\
\text { chromosome, } \\
\text { total }\end{array}$} & \multirow{3}{*}{$\begin{array}{c}\text { Student's } \\
\text { test }\end{array}$} \\
\hline & \multicolumn{3}{|c|}{ Asian Y chromosome } & $\begin{array}{l}\text { European Y } \\
\text { chromosome }\end{array}$ & & \\
\hline & MS2853 & MS2987 & VTN300 & LNDR07 & & \\
\hline Number of animals & 85 & 291 & 90 & 94 & 466 & - \\
\hline $\operatorname{Mean}\left(X \pm s_{x}\right)$ & $3.20 \pm 0.11$ & $3.25 \pm 0.04$ & $3.21 \pm 0.07$ & $3.42 \pm 0.10$ & $3.23 \pm 0.04$ & 1.76 \\
\hline Dispersion $\left(S^{2}\right)$ & 0.941 & 0.563 & 0.490 & 0.903 & 0.615 & 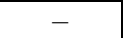 \\
\hline $\begin{array}{c}\text { Number of live } \\
\text { piglets at the age of } 6 \\
\text { days }\end{array}$ & 351 & 645 & 276 & 359 & 1272 & - \\
\hline $\begin{array}{c}\text { Number of piglets } \\
\text { culled at the age of } 1 \\
\text { month }\end{array}$ & 10 & 12 & 8 & 36 & 30 & - \\
\hline $\begin{array}{c}\text { Proportion of piglets } \\
\text { culled at the age of } 1 \\
\text { month }(\%)\end{array}$ & $\begin{array}{c}2.849 \pm \\
0.888\end{array}$ & $\begin{array}{l}1.860 \pm \\
0.532\end{array}$ & $\begin{array}{c}2.899 \pm \\
1.010\end{array}$ & $\begin{array}{c}10.028 \pm \\
1.585\end{array}$ & $\begin{array}{c}2.358 \pm \\
0.425\end{array}$ & $\begin{array}{c}4.57 \\
\mathrm{P}<0.001\end{array}$ \\
\hline
\end{tabular}

After the different effects of Y-chromosome genes of European and Asian origin on the weight of a newborn piglet were found, the question arose of whether this effect is limited only to prenatal period or extends to later postnatal one. This study showed that at one month of age, when weaned from mother, differences in live weight of piglets - offspring of different boar lines, are statistically insignificant (Barlett's test $\chi^{2}=19.368 ; d$.f. $=42$. Ftest $F=1.445 ; \mathrm{P}=0.228843$ ) (Table 4 ). However, in accordance with the practice accepted in "Mini-Pig Farm" of the ICG SB RAS, visual assessment of piglets is conducted first before weaning. Animals with defects in exterior, sickly look, signs of underdevelopment and underfeeding, or other deviations from normal parameters should be culled without weighing. This practical solution is fully methodologically reasonable but, at the same time, a significant part of small, light-weight animals drop off the researchers' radar. As a result, average weight value at the age of one month is artificially aligned and overestimated. Therefore, for assessing growth rate from birth to one month of age, an indirect method can be used - comparing groups of the descendants of boars of different lines according to the proportion of culled animals, since the latter include piglets with significant growth retardation. The comparison showed that in the carrier line of European Y chromosome the number of culled animals is statistically significantly $(\mathrm{P}<0.001)$ greater than in the carrier lines of Asian Y chromosome (Table 4). This is also confirmed by pair wise comparisons. All differences between the carrier lines of Asian Y-chromosome are statistically insignificant (Student's criterion 0.96, 0.10 and 0.91 for pairs MS2853-MS2987, MS2853- 
VTN300 and MS2987-VTN300, respectively). At the same time, the proportion of culled piglets in LNDR07 line was significantly $(\mathrm{P}<0.001)$ higher than values obtained for the carrier lines of Asian Y chromosome (Student's criterion 3.95, 4.89 and 3.79 when compared with MS2853, MS2987, and VTN300, respectively). Thus, despite the fact that the results of a direct comparison of the lines of boars by the weight of offspring at the age of one month revealed no differences, an indirect assessment of differences based on a comparison of the number of culled piglets indicates the possibility of such relationship with the retaining of tendencies in weight found at birth. In addition, since light-weight piglets with sickly look are culled, it can be assumed that European Y chromosome is poorly compatible with Asian allele pool which prevails in mini pigs of the ICG SB RAS. This can lead to a sickly look with signs of exhaustion and stunted growth.

\section{Discussion}

In this research, the question was solved about the differences between Y chromosomes of the genealogical lines of mini pigs of the ICG SB RAS - other than the origin (European or Asian) $[34,35]$. Statistical analysis showed that boar lines marked with Y-chromosomes of European (one line) and Asian (three lines) origin statistically differ in the average weight of a newborn offspring, that is, in the growth rate during prenatal period (Table 1). In addition, the study showed that this difference can persist in early postnatal period (at least, until the age of one month). It is of particular interest that the size of newborns in the line carrying Y-chromosome of European breed with large-sized piglets was statistically significantly less than in lines carrying $\mathrm{Y}$-chromosome of Asian breed with small-sized newborns. This fact is even than strange, since in theory, it should have been exactly the opposite. To explain this unexpected phenomenon, three hypotheses can be proposed; in two of them possible scenarios for the formation of differences between European and Asian Y chromosomes are considered, and in the third one, a possible explanation of the situation in the breeding group of mini-pigs of the ICG SB RAS is proposed.

- Hypothesis 1.In the genome of large European breeds including those originating from English marching pig [36], there is non-Y chromosome factor that provides intensive growth in pre- and postnatal periods [37, 38]. Possibly, there is an extended duration of the effect of this gene that controls intensive prenatal growth for the postnatal period what led to literally "explosive" (compared with wild boars and primitive breeds) growth of young pigs of modern breeds in the first year of life [39]. Effect of European non-Y chromosome factor is many times greater than this of $\mathrm{Y}$ chromosome gene complex which performs a similar function. In such situation, it its partial mutational destruction and, accordingly, increasing weakening of efficiency is quite possible. In wild boars, weight of a newborn piglet varies within the same limits as in European breeds [16]; therefore, trait value characteristic for European breeds should be considered as primary one in relation to Asian breeds. With the destruction of Y-chromosomal gene complex in European breeds, the size of newborns should become less than that of wild boars but this fact is not described by anyone. In Asian breeds having no non-Y chromosome growth factor similar to the European one, the effect of Y chromosome genes could remain unchanged. However, not only the relative contribution of $\mathrm{Y}$ chromosome increased, but also the absolute value of this contribution (Table 3). Therefore, decrease in the weight of a newborn piglet in Asian breeds with simultaneously increased contribution of Y chromosome to this trait seems to be more likely.

- Hypothesis 2. Some of the Y chromosomes of mini-pigs of the ICG SB RAS could be inherited from small-sized Vietnamese breed with large litter [23, 40] which is characterized by reverse sexual dimorphism in live weight [33]. Along with decreasing weight of a newborn piglet, due to the large number of offspring with relatively small size 
of mother, a mutation (or mutations) could occur that increases the weight of newborn males. Increased birth weight increases weight at weaning and the chances of getting into reproductive group [41]. Therefore, such mutation could be fixed in Vietnamese breed as a kind of compensation for the action of non-Y chromosome genes which reduce birth weight in both sexes.

- Hypothesis 3.In the breeding group of mini-pigs of the ICG SB RAS, a part of genome predominates that was inherited from small-sized Asian domestic pig. It is possible that gene complex of European Y chromosome does not combine well with the Asian part of the allele pool of mini-pigs of the ICG SB RAS. In this case, there may be a decrease in adaptation which may also be evident in the form of growth retardation during prenatal period. However, such incompatibility should be with a high probability accompanied by an increased proportion of stillborn and weak piglets dying in early postnatal period during feeding of piglets by their mother. The comparison showed that the proportion of such animals in the offspring of carriers of European Y-chromosome is $25.219 \pm 2.034 \%$ (115 of 456) while in carriers of Asian Y-chromosome it is $19.819 \pm 1.013 \%$ (307 of 1549). The difference is $5.40 \pm 2.272 \%$ and it is statistically significant (Student's criterion 2.38, P $<0.05$ ). By the way, a high percentage of culling can also indicate this fact (Table 4). So, this hypothesis can be accepted. However, it does not excludebut only supplements the two previous hypotheses, so the question of the origin of differences in gene complexes of the European and Asian Y chromosomes remains open.

\section{Conclusions}

The results of study show a difference in the live weight of newborn piglets born from boars of different lines in a small highly inbred population which indicates to the presence of a certain genetic agent specific to each line. The most likely differentiation of the live weight of newborn piglets of separate lines is due to various in the molecular structure of the $\mathrm{Y}$ chromosome, especially since similar results were previously obtained in mice. Moreover the combination of our results with the literature data indicates rather than the various effect of $\mathrm{Y}$ chromosomes of separate genealogical lines, but rather the different effect of the European and Asian Y chromosomes on the live weight of piglets at birth. However at the moment it is not possible to indicate the effect of a specific gene which gives the perspective for further research.

\section{Conflict of interest}

We certify that there is no conflict of interest with any financial organization regarding the material discussed in the manuscript.

\section{Acknowledgments}

The work is supported by budget funding under the state project (No. AAAA-A17117071240065-4).

\section{References}

1. M. Ridley. Genome: the Autobiography of a Species in 23 Chapters (Published by Harper Perennial: Paperback, 2006). 
2. V.A. Trifonov. Origin and evolution of vertebrate sex chromosomes (D Thesis, Institute of Molecular and Cellular Biology SB RAS, Novosibirsk, Russia, 2018).

3. J.F. Ouimette, C. Rougeulle, Adv Exp Med Biol.; 886, 33-49, (2016) doi: 10.1007/97894-017-7417-8_3

4. B. Lewin, Genes IX (Jones \& Bartlett Learning, 2008)

5. M.N. Choudhury, A. Uddin, S. Chakraborty, Genetica, 145 (3), 295-305 (2017) doi: 10.1007/s10709-017-9965-y

6. A.A. Maan, J. Eales, A. Akbarov, J. Rowland, X. Xu, M.A. Jobling, J. Fadi, F.J. Charchar, M. Tomaszewski,. Eur J Hum Genet, 25, 1181-1188 (2017) doi: 10.1038/ejhg.2017

7. J.F. Hughes, D.C., Annu Rev Genet. 49: 507-527 (2015) doi: 10.1146/annurev-genet112414-055311

8. S. Colaco, D. Modi, Reproductive Biology and Endocrinology, 16, 14 (2018) doi:10.1186/s12958-018-0330-5

9. I. Martincová, L. Dureje, J. Kreisinger, M. Macholán, J. Piálek, EcolEvol, 9 (10), 61246137 (2019) doi: 10.1002/ece3.5196.

10. S.V. Nikitin, S.P. Knyazev, G.M. Goncharenko, V.A. Bekenev, Russ. J. Genet, 4 (4), 416-423 (2007).

11. I. Declerck, S. Sarrazin, J. Dewulf, D. Maes, Animal, 11 (8), 1336-1343 (2017) doi: $10.1017 /$ S1751731117000131

12. S.V. Nikitin, S.P. Knyazev, V.I. Ermolayev, Vavilov Journal of Genetics and Breeding, 21 (5), 569-575 (2017). doi: 10.18699/VJ17.273

13. C. Colleton, D. Brewster, A. Chester, D.O. Clarke, P. Heining, A. Olaharski, M. Graziano, ToxicolPathol, 44 (3), 458-466 (2016) doi: 10.1177/ 0192623315617562.

14. P. Heining, T. Ruysschaert, The use of minipig in drug discovery and development: pros and cons of minipig selection and strategies to use as a preferred non rodent species, ToxicolPathol, 44 (3), 467-473 (2016) doi: 10.1177/0192623315610823

15. T. Nunoya, K. Shibua, T. Saitoh, H. Yazawa, K. Nakamura, Y. Baba, T. Hirai, J. Toxicol Pathol, 20, 125-132 (2007) doi: 10.1293/tox.20.125

16. V.N. Tikhonov, Laboratory Minipigs. Genetics and biomedical use (Novosibirsk: SB RAS Publ., 2010)

17. S.V. Nikitin, S.P. Knyazev, K.S. Shatokhin, V.I. Zaporozhets, V.I. Ermolaev, Vavilov Journal of Genetics and Breeding, 22(8), 922-930 (2018) doi10.18699/VJ18.434

18. N.V. Stankova, M.A. Savina, G.D. Kapanadze, Biomeditsina = Biomedicine, 3, 95-101 (2017)

19. S.G. Inge-Vechtomov. Genetics with the basics of breeding (Moscow, Vyschayashkola, 1989)

20. S.V. Nikitin, S.P. Knyazev. Selection and adaptation in domestic pig populations (Saarbrucken: Lambert Academy Publ., 2015.)

21. V.A. Bekenev. Technology of Pig Keeping and Breeding (St. Petersburg: Lan Publ., 2012)

22. Norms and diets of feeding of farm animals. Handbook. Under the editorship A.P. Kalashnikov. 3rd edition revised and supplemented (Moscow, Russian Agricultural Academia of Science, 2003)

23. S.V. Nikitin, S.P. Knyazev, K.S. Shatokhin. Russ. J. Genet.: Appl.Res, 4(6), 511-522 (2014) doi: 10.1134/ S207905971406015X.

24. K.S. Shatokhin, S.V. Nikitin, S.P. Knyazev, G.M. Goncharenko, V.I. Ermolaev, V.I. Zaporozhets Livestock, physiology and genetic of the mini-pigs of ICG SB RAS (Novosibirsk, Siberian Federal Research Centre for Agro Biotechnology Publ., 2019).

25. Theory of statistics, Under the editorship prof. G.L. Gromyko. Second edition (Moscow, "INFRA-M", 2010) 
26. L.N. Bolshev, N.V. Smirnov Tables of mathematical statistics (Moscow, "Nauka", 1983)

27. L.A. Zhivotovskiy. Populational Biometry (Moscow, Nauka Publ., 1991)

28. O. Ramírez, et al., MolBiolEvol. 9, 2061-2072 (2009) doi: 10.1093/molbev/msp118.

29. N.M. Hall, G.M. Brown, R.A. Furlong, C.A. Sargent, M. Mitchell, D. Rocha, N.A. Affara., Mamm Genome, 14, 437-447 (2003) doi: 10.1007/s00335-002-3068-4

30. K. Kawasaki, M. Mikami, M. Goto, J. Shindo, M. Amano, M. Ishiyama, J MolEvol. 88, 122-135 (2020) doi: 10.1007/s00239-019-09917-0.

31. N. Li, W. Ma, Q. Shen, M. Zhang, Z. Du, C. Wu, B. Niu, W. Liu, J. Hua, Cell Death Differ, 26 (10), 2115-2124 (2019) doi: 10.1038/s41418-019-0280-2.

32. K.B. Shpargel, T. Sengoku, S. Yokoyama, T. Magnuson, PLoS Genet. 8(9), e1002964 (2012) doi: 10.1371/journal.pgen.1002964.

33. S.V. Nikitin, S.P. Knyazev, K.S. Shatokhin, G.M. Goncharenko, V.I. Ermolayev, Vavilov Journal of Genetics and Breeding, 19 (5), 624-629 (2015) doi: $10.18699 / \mathrm{VJ} 15.079$

34. G. Larson, et al., Science, 307 (5715), 1618-1621 (2005) doi: $10.1126 /$ science. 1106927

35. S. Guirao-Rico, O. Ramirez, A, Ojeda, M. Amills, S.E. Ramos-Onsins, Heredity, 120, 63-76 (2018) doi: 10.1038/s41437-017-0002-9

36. V. Porter. Pigs. A handbook to the breeds of the world. (Helm Information. Ltd.Mountfield, United Kingdom, 1993)

37. W. Pond, K. Haupt. The biology of the pig (Ithaca: Comstock Publishing Associates, 1978)

38. D. Surek, L. N. E. Barrilli, I. J. M. Bueno, E. L. Krabbe, G. C. Alberton, A. Maiorka, J Anim Sci. 92, 177-181 (2014) doi: 10.2527/jas.2013-6651

39. S.P. Knyazev, K.S. Shatokhin, G.M. Goncharenko, V.I. Frolova, V.I. Zaporozhets, V.I. Ermolaev, S.V. Nikitin, Science Review, 6, 9-13, (2015)

40. L.T.T. Huyen, R. Roessler, U. Lemke, A. Valle Zárate. Impact of the use of exotic compared to local pig breeds on socio-economic development and biodiversity in Vietnam (Verlag Grauer, Beuren, Stuttgart, 2005).

41. V.D. Kabanov. Increasing Pig Productivity, (Moscow, Kolos Publ., 1983) 